\title{
Ação de extrato de folhas de Acmella oleracea (L.) R. K. Jansen em co-cultivo de Staphylococcus aureus e L929 (fibroblastos) simulando processo de celulite infecciosa
}

Action of Acmella oleracea (L.) R. K. Jansen leaves extract in co-cultivation of Staphylococcus aureus AND L929 (fibroblasts) simulating infectious cellulite process

Acción de Acmella oleracea (L.) R. K. Jansen extracto de hojas en cocultivo de Staphylococcus aureus Y L929 (fibroblastos) simulando el proceso de celulitis infecciosa

\section{Resumo}

Introdução: A bactéria Staphylococcus aureus é o agente etiológico de maior incidência nas infecções de pele, dentre elas a celulite infecciosa. Seu tratamento é contido por antibióticos, porém o uso de plantas medicinais vem sendo utilizadas para tratamento. Acmella oleracea é uma planta da família Asteraceae conhecida como jambu. Objetivos: Avaliar a ação do extrato das folhas de Acmella oleracea em co-cultivo da linhagem celular L929 e bactérias Staphylococcus aureus simulando o processo de celulite infecciosa. Metodologia: Foi realizado primeiramente o teste MTT e Cristal Violeta na linhagem celular L929 incubadas com o extrato do jambu, nas concentrações $500 \mu \mathrm{g} / \mathrm{mL}$, $1000 \mu \mathrm{g} / \mathrm{mL}$ e $2000 \mu \mathrm{g} / \mathrm{mL}$. Foi realizado ensaios com Staphylococcus aureus incubado no período de 24 horas com o extrato do jambu nas mesmas concentrações. Resultados: Na avaliação das células L929 no teste MTT houve uma significância na concentração de $1000 \mu \mathrm{g} / \mathrm{mL}$ apresentando uma baixa atividade metabólica em relação as outras concentrações. No teste cristal violeta ocorreu um maior estímulo nas demais concentrações quando comparado ao controle. Na viabilidade da bactéria observou-se uma queda significativa da viabilidade quando comparado ao controle. A concentração de $500 \mathrm{ug} / \mathrm{mL}$ foi que apresentou um menor índice de UFC. Ao realizar o teste do co-cultivo L929 - S. aureus após a incubação de 24 horas com diferentes concentrações do extrato, foi possível avaliar que a ação do extrato apresentou uma redução significativa na viabilidade bacteriana e não interferência à viabilidade das células L929. Conclusão: Com estes resultados demonstramos que o extrato de Acmella oleracea apresentou uma atividade antimicrobiana sem interferir na linhagem de fibroblastos L929, sendo assim podendo ser utilizada contra a celulite infecciosa.

Palavras-chave: Estafilococo; Fibroblasto de camundongo; Jambu; Viabilidade celular.

\begin{abstract}
Introduction: Staphylococcus aureus bacteria is the etiological agent with the highest incidence in skin infections, including infectious cellulitis. Its treatment is contained by antibiotics, but the use of medicinal plants has been used for treatment. Acmella oleracea is a plant of the Asteraceae family known as jambu. Objectives: To evaluate the action of Acmella oleracea leaf extract in co-cultivation of the L929 cell line and Staphylococcus aureus bacteria, simulating the process of infectious cellulitis. Methodology: The MTT and Crystal Violet test was first performed on the L929 cell line, incubated with jambu extract, at concentrations of $500 \mu \mathrm{g} / \mathrm{mL}, 1000 \mu \mathrm{g} / \mathrm{mL}$ and $2000 \mu \mathrm{g} / \mathrm{mL}$. Tests were carried out with Staphylococcus aureus incubated for a period of 24 hours with jambu extract at the same concentrations. Results: In the evaluation of L929 cells in the MTT test, there was a significance in the concentration of $1000 \mu \mathrm{g} / \mathrm{mL}$ showing a low metabolic activity compared to other concentrations. In the crystal violet test there was
\end{abstract}


a greater stimulus in the other concentrations when compared to the control. In bacterial viability, a significant drop in viability was observed when compared to the control. The concentration of $500 \mu \mathrm{g} / \mathrm{mL}$ showed the lowest CFU index. When performing the L929 - S. aureus co-cultivation test after incubation for 24 hours with different concentrations of the extract, it was possible to assess that the action of the extract presented a significant reduction in bacterial viability and did not interfere with the viability of L929 cells. Conclusion: With these results we demonstrate that the Acmella oleracea extract presented an antimicrobial activity without interfering with the L929 fibroblast lineage, thus being able to be used against infectious cellulitis.

Keywords: Staphylococcus; Mouse fibroblast; Jambu; Cell viability.

\section{Resumen}

Introducción: La bacteria Staphylococcus aureus es el agente etiológico de mayor incidencia en las infecciones cutáneas, incluida la celulitis infecciosa. Su tratamiento está contenido por antibióticos, pero se ha utilizado el uso de plantas medicinales para el tratamiento. Acmella oleracea es una planta de la familia Asteraceae conocida como jambu. Objetivos: Evaluar la acción del extracto de hoja de Acmella oleracea en el co-cultivo de la línea celular L929 y la bacteria Staphylococcus aureus, simulando el proceso de celulitis infecciosa. Metodología: La prueba MTT y Crystal Violet se realizó primero en la línea celular L929, incubada con extracto de jambu, a concentraciones de 500 $\mu \mathrm{g} / \mathrm{mL}, 1000 \mu \mathrm{g} / \mathrm{mL}$ y $2000 \mu \mathrm{g} / \mathrm{mL}$. Las pruebas se realizaron con Staphylococcus aureus incubado por un período de 24 horas con extracto de jambu a las mismas concentraciones. Resultados: En la evaluación de células L929 en la prueba MTT, hubo una significancia en la concentración de $1000 \mu \mathrm{g} / \mathrm{mL}$ mostrando una baja actividad metabólica en comparación con otras concentraciones. En la prueba de violeta cristal hubo un mayor estímulo en las otras concentraciones en comparación con el control. En la viabilidad bacteriana, se observó una caída significativa en la viabilidad en comparación con el control. La concentración de $500 \mu \mathrm{g} / \mathrm{mL}$ mostró el índice de UFC más bajo. Al realizar la prueba de co-cultivo L929 - S. aureus luego de 24 horas de incubación con diferentes concentraciones del extracto, se pudo evaluar que la acción del extracto presentó una reducción significativa en la viabilidad bacteriana y no interfirió con la viabilidad de células L929. Conclusión: Con estos resultados demostramos que el extracto de Acmella oleracea presentó actividad antimicrobiana sin interferir con el linaje de fibroblastos L929, pudiendo así ser utilizado contra la celulitis infecciosa.

Palabras clave: Staphylococcus; Fibroblasto de ratón; Jambu; Viabilidad celular.

\section{Introdução}

As infecções bacterianas na pele são decorrentes de vários fatores, dentre eles, os ambientais e indivíduos como falta de higiene, baixa resistência imunológica, diabetes mellitus, predisposição genética, assim como os fatores associados ao grau de virulência e patogenicidade do microrganismo. Os principais agentes são as bactérias do gênero Staphylococcus e Streptococcus (Pires et al., 2015).

Os Staphylococcus são bactérias gram-positivas e/ou anaeróbicas facultativas, são encontrados principalmente na pele, podendo tornar-se patogênico em condições como a quebra de barreira cutânea ou diminuição da imunidade. É responsável por várias infecções, como infecções na pele e no subcutâneo, infecções pós-cirúrgicas, abscessos e bacteremia (Gelatti et al., 2009). Podem causar diversos processos infecciosos, desde infecções cutâneas crônicas até infecções sistêmicas, podendo atingir os tecidos mais profundos. A resistência do S. aureus aos antibióticos tem sido desenvolvida por mutações em seus genes ou pela aquisição de genes de resistência de outras bactérias das mesmas espécies (Santos et al., 2007). A bactéria Staphylococcus aureus é o agente etiológico de maior incidência nas infecções de pele, desde as mais simples como celulites, furúnculo, impetigo até infecções como pneumonias, meningite, endocardite, entre outras.

Dentre as infecções de pele, encontra-se a celulite infecciosa, que é caracterizada como uma infecção que atinge a derme profunda, epiderme e tecido subcutâneo. As bactérias espalham-se rapidamente sobre uma grande área impedindo que os tecidos limitem a extensão da infecção. A sua etiologia ocorre em $75 \%$ dos casos relacionado à infecção pelo Staphylococcus (Pires et al., 2015) e, em geral, espalham-se numa área mais reduzida (Brum et al., 2016). A celulite infecciosa manifesta sinais locais de inflamação (eritema, edema, calor e dor) e na maioria febre e leucocitose. Os fatores de risco sistêmicos gerais incluem insuficiência venosa, linfedema, doença vascular periférica, diabete e obesidade. Em relação aos fatores locais incluem úlceras, trauma e picadas de inseto. A celulite infecciosa desenvolve no geral nas pernas. A infecção aparece depois de a pele ter sido danificada devido a uma lesão, ulceração ou dermatite. As zonas da pele que incham devido 
ao líquido exsudado (edema) são mais vulneráveis (Brum et al., 2016). O diagnóstico clínico e tratamento consiste em medidas de suporte, elevar membros acometidos e antibioticoterapia. Deve durar de 5 até 14 dias a depender da gravidade ou resposta clínica aos primeiros dias do antibiótico. (Souza, 2003).

No Brasil, somente $20 \%$ da população consome $63 \%$ dos medicamentos, enquanto o restante encontra nos medicamentos de origem natural, especialmente nas plantas medicinais, a única fonte de recurso terapêutico. Há um grande avanço científico envolvendo estudos químicos e farmacológicos de plantas medicinais, obtendo novos compostos com propriedades terapêuticas. A organização Mundial de Saúde (OMS) estima que 65-80\% das pessoas nos países confiam na medicina tradicional para assistência primária de saúde e que 85\% desta medicina envolvem o uso de extratos de plantas (Haida et al., 2007). As plantas medicinais vêm sendo utilizadas para tratamento, cura e prevenção de doenças (Martins, 2016). Neste contexto, um estudo visando determinar o potencial da atividade antibacteriana dos extratos aquosos de várias plantas medicinais em bactérias de importância em alimentos foi realizado (Ferreira et al., 2020). Os resultados evidenciaram o efeito bactericida destes extratos sobre as bactérias

Uma destas plantas é a Acmella oleracea conhecida no Brasil principalmente como jambu, identificada entre uma das espécies de grande relevância de sua família, Asteraceae, que possui cerca de 25.000 espécies distribuídas aproximadamente entre 1000 gêneros botânicos. A. oleracea é nativa da região Amazônica brasileira, principalmente do estado do Pará conhecida por suas propriedades anti-inflamatórias e antibacterianas (Ojeda, 2017). Do extrato das folhas de A. oleracea é extraído o óleo essencial com índice elevado de uma substância conhecida como espilantol, uma $\mathrm{N}$-isobutilamida responsável pelas propriedades bioatividades anti-inflamatórias, antissépticas e anestésicas da planta e também induz a atividade de eliminação de radicais livres e inibe a transcrição inflamatória na dermatite e pancreatite (Meireles, 2016; Chagas, 2020). Devido à presença desta substância, a planta possui aplicação tradicional em produtos farmacêuticos, alimentos e produtos para a saúde e cuidados pessoais. Assim, pensando-se na vasta biodiversidade Amazônica, a utilização de plantas é extremamente promissora e pode ser conduzida com amplas possibilidades de novas descobertas, podendo causar impactos positivos, como, em doenças infecciosas, cânceres, em diversas áreas das ciências da saúde.

Desta forma, o objetivo do presente estudo é avaliar a ação do extrato das folhas de Acmella oleracea sob a bactéria Staphylococcus aureus e em células L929 simulando o desenvolvimento da celulite infecciosa.

\section{Metodologia}

Esse estudo experimental, in vitro, utilizou um método hipotético dedutivo, com abordagem quantitativa através da análise estatística dos dados recolhidos (Pereira et al., 2018). Para todos os experimentos foram realizadas análises estatísticas no programa GraphPad Prism®, versão 5.01 - 1992-2007. As médias dos dados foram comparadas pelo teste ANOVA seguido por Tukey, estabelecendo o nível de significância de $5 \%(\mathrm{p} \leq 0,05)$. Os dados são apresentados como média e desvio padrão. Todos os experimentos foram realizados em triplicata com dois experimentos independentes.

\subsection{Origem do extrato}

Todo o processamento para obtenção do extrato utilizado no presente trabalho foi realizado por Silva (2021), onde foi feito o cultivo da planta medicinal no Centro de Estudos da Natureza (CEN) da Universidade do Vale do Paraíba (UNIVAP) em São José dos Campos-SP. O processo de extração e o fracionamento líquido-líquido foi realizado no laboratório de Síntese Orgânica, localizado no Instituto de Pesquisa e Desenvolvimento (IP\&D) da UNIVAP.

No presente trabalho a membrana contendo extrato bruto foi dissolvida em metanol em tubo Falcon $(50 \mathrm{~mL}) \mathrm{em}$ agitador Vortex (Global Trade Technology/ XH-C). Para a realização dos experimentos o extrato foi diluído em meio de cultura meio MEM (Minimum Essential Medium - Gibco) suplementado com $5 \%$ de SFB e $1 \%$ antibiótico/antimicótico, 
separados em tubos Falcon (15 mL) nas concentrações $500 \mathrm{ug} / \mathrm{mL}, 1000 \mathrm{ug} / \mathrm{mL}$ e $2000 \mathrm{ug} / \mathrm{mL}$ sendo utilizadas em todos os experimentos.

\subsection{Linhagem Celular}

A linhagem celular clone L929 (ATCC CCL-1 NCTC) é uma linhagem contínua de fibroblastos de camundongo. Para o presente estudo, optou-se pela sua utilização, pois tem sido modelo em testes de citotoxicidade/viabilidade celular segundo a ISSO 10993. A mesma foi adquirida do Laboratório de Cultura de Células do Instituto Adolfo Lutz, São Paulo, SP, Brasil.

Para o cultivo da linhagem celular L929, as células foram mantidas em garrafas de cultura $75 \mathrm{~cm}^{2}$ com meio MEM (Minimum Essential Medium - Gibco) suplementado com 5\% de SFB (Gibco® - Life Technologies) e 1\% antibiótico/antimicótico (Gibco® - Life Technologies) e incubadas em estufa a $37^{\circ} \mathrm{C}$ e pressão de $5 \%$ de $\mathrm{CO}_{2}($ Forma Scientific $\mathrm{CO}_{2}$ Water Jacketed incubator - Instrucom Ltda). O crescimento celular foi acompanhado por meio de observações diárias em microscópio invertido Olympus CK40 e o meio trocado a cada dois dias.

Para a realização dos experimentos as células foram removidas das garrafas de cultura e passadas para placas de cultura de 24 poços. Foram utilizados $1 \times 10^{5}$ células/mL em cada poço e calculada a diluição do extrato e do meio de cultura necessários para as diferentes concentrações de extrato. Após plaqueadas, as células foram incubadas em estufa a $37^{\circ} \mathrm{C}$ e $5 \%$ de $\mathrm{CO}_{2}$ por 24 horas. Em seguida, as células foram observadas no microscópio invertido Olympus CK40 e nestas células foi trocado o meio de cultura no grupo controle e foram adicionados os extratos em concentrações de $500 \mu \mathrm{g} / \mathrm{mL}, 1000 \mu \mathrm{g} / \mathrm{mL}$ e $2000 \mu \mathrm{g} / \mathrm{mL}$ e em seguida foram incubadas em estufa a $37^{\circ} \mathrm{C}$ e pressão de $5 \%$ de $\mathrm{CO}_{2}$ por 24 horas.

\subsection{Determinação da viabilidade celular}

\subsubsection{Teste MTT}

A fim de verificar a atividade mitocondrial e mensurar a viabilidade da linhagem L929 as células foram submetidas ao teste MTT [3 - (4, 5-dimetiltiazol-2-y1) -2, brometo de 5-difeniltetrazólio]. Após 24 horas de incubação de diferentes concentrações do extrato, o meio de cultivo foi descartado e os poços foram lavados com PBS, em seguida foi adicionado 300 $\mu \mathrm{L}$ de MTT a $5 \mathrm{mg} / \mathrm{mL}$ diluído em PBS e incubada por 2 horas em condições de cultivo e ausência de luz a $37^{\circ} \mathrm{C}$ em estufa. Seguidamente a solução de MTT foi retirada e foram adicionados $200 \mu \mathrm{L}$ de DMSO (Dimetilsulfóxido - Sigma - Aldrich®) por poço, sendo a placa submetida à agitação por 30 minutos para diluição dos cristais de formazana. Em seguida, foi realizado a leitura da absorbância em espectrofotômetro Elisa Spectra CountTM Packard, USA a 570 nm.

\subsubsection{Cristal Violeta}

Para avaliar a densidade celular após tratamentos, as células foram submetidas ao teste cristal violeta (CV), que consiste na incorporação do corante ao DNA. Retirado seu excesso, a absorbância é proporcional à quantidade de células na amostra (Castro-Silva et al.,2009).

Após 24 horas de incubação de diferentes concentrações do extrato, o meio de cultivo da placa foi retirado, os poços foram lavados com PBS e em seguida foi adicionado nos poços $300 \mu \mathrm{L}$ da solução de coloração de Cristal Violeta (5\% de CV, $1,7 \%$ de $\mathrm{NaCl}, 3,3 \%$ de paraformaldeído, 33,3\% de etanol e 56,7\% de água) por 3 minutos. Posteriormente, as placas foram lavadas em água corrente por 2 minutos. Em seguida, foram adicionados $300 \mu \mathrm{L}$ de DMSO (Dimetilsulfóxido - Sigma Aldrich $囚)$ e mantidas por 1 hora no escuro em temperatura ambiente para a eluição das células. A leitura da absorbância foi realizada em espectrofotômetro Elisa Spectra CountTM Packard, USA a $570 \mathrm{~nm}$. 


\subsection{Ativação de cepa bacteriana}

Para a ativação da cultura bacteriana a cepa padrão Staphylococcus aureus (ATCC n²5923) foi incubada em meio BHI (Brain Heart Infusion - Sigma - Aldrich $®$ ) por 24 horas a em estufa $37^{\circ} \mathrm{C}$. Após este período foi feita a leitura de uma alíquota da cultura $(200 \mu \mathrm{L})$ em espectrofotômetro (Elisa Spectra CountTM Packard, USA) utilizando filtro de $570 \mathrm{~nm}$. Os valores das leituras de absorbância óptica correlacionam-se com a concentração de células em unidades formadoras de colônias (UFC) por $\mathrm{mL}$ de solução. Essa correlação é mostrada na equação $\mathrm{Y}=-0,173+21,186 \mathrm{X}$ segundo Arcos et al. (2004), onde $\mathrm{Y}$ é a concentração de células em UFC por mL de solução e X é a absorbância das culturas bacterianas. Seguindo essa equação, o resultado obtido para Y deve ser multiplicado por $10^{8}$.

\subsection{Atividade antibacteriana}

Em placas de cultura de 24 poços contendo cada poço $500 \mu \mathrm{L}$ de meio LB foi adicionada $5 \mu \mathrm{L}$ de cultura de $S$. aureus, e complementado com o extrato de A. oleracea em concentrações de $500 \mu \mathrm{g} / \mathrm{mL}, 1000 \mu \mathrm{g} / \mathrm{mL}$ e $2000 \mu \mathrm{g} / \mathrm{mL}$ sendo incubadas em estufa por 24 horas.

Após 24 horas de incubação foram retirados $200 \mu \mathrm{L}$ do sobrenadante dos poços e transferidos para placa de 96 poços. Foi realizada diluição seriada e realizado a leitura da absorbância em espectrofotômetro Elisa Spectra CountTM Packard, USA a $570 \mathrm{~nm}$.

\subsection{Co-cultivo da linhagem L929 e Staphylococcus aureus}

As células da linhagem L929 foram cultivadas em placas de 24 poços com meio MEM suplementado com 5\% de SFB e $1 \%$ antibiótico/antimicótico e incubadas em estufa a $37^{\circ} \mathrm{C}$ e $5 \%$ de $\mathrm{CO}_{2}$ por 24 horas. Logo após foi retirado todo o meio e adicionado meio novo em todos os poços e em seguida acrescentado $10 \mu \mathrm{L}$ da cultura bacteriana $S$. aureus em todos os poços, sendo incubada em estufa a $37^{\circ} \mathrm{C}$ e pressão de $5 \%$ de $\mathrm{CO}_{2}$ por 5 horas. Passado este período foram adicionados os extratos de A. oleracea nas concentrações de $500 \mu \mathrm{g} / \mathrm{mL}, 1000 \mu \mathrm{g} / \mathrm{mL}$ e $2000 \mu \mathrm{g} / \mathrm{mL}$ diluídos em meio MEM, incubados em estufa por 24 horas.

Após 24 horas foram retirados $200 \mu \mathrm{L}$ de cada poço para uma placa de 96 poços para realizar a leitura no sobrenadante da bactéria $S$. aureus no espectrofotômetro a $570 \mathrm{~nm}$. O meio restante de cada poço da placa de 24 poços foi descartado e foi avaliada a viabilidade celular da linhagem L929 pelo teste MTT.

\section{Resultados e Discussão}

\subsection{Resultados}

\subsubsection{Determinação da viabilidade celular na linhagem L929}

\subsubsection{Ensaio de citotoxicidade (MTT)}

O teste MTT baseia-se na redução do sal tetrazolato pela enzima hidrogenase succínia presente na mitocôndria das células, as quais adquirem uma coloração violácea que é medida por espectrofotometria. Este teste é empregado para avaliar a atividade metabólica das células. 
Figura 1 - Avaliação da atividade metabólica (MTT) na linhagem celular L929 frente a diferentes concentrações do extrato de A. oleracea.

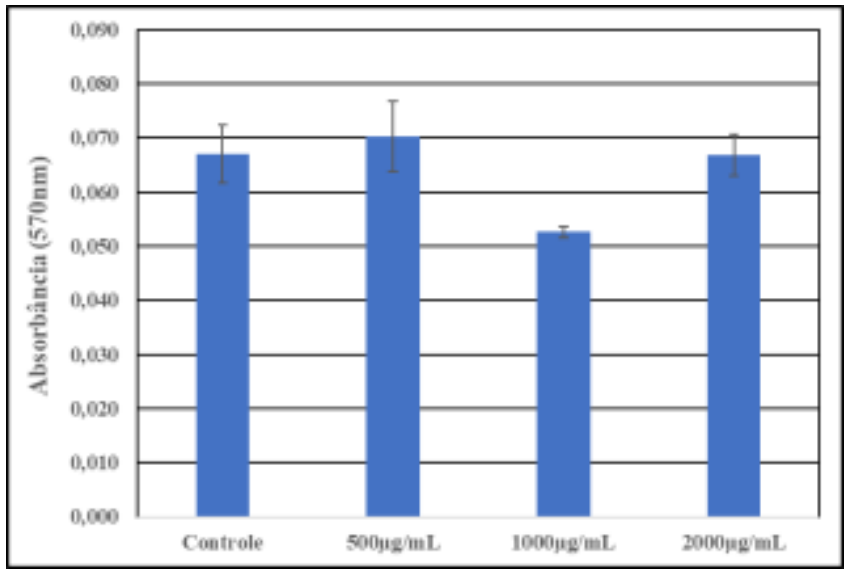

Fonte: Autores.

De acordo com os resultados obtidos da avaliação da atividade metabólica com o método de MTT, representada na Figura 1, observou-se que o extrato de A. oleracea na concentração de $1000 \mu \mathrm{g} / \mathrm{mL}$ induziu baixa atividade metabólica nas células sendo esta diferença significativa em relação as outras concentrações.

\subsubsection{Ensaio de citotoxicidade (Cristal Violeta)}

O corante cristal violeta é utilizado para determinar a densidade celular devido a sua habilidade de ligação ao DNA. Após sua eluição, este também pode ser mensurado espectofotometricamente.

Figura 2 - Avaliação da proliferação celular (Cristal Violeta) na linhagem celular L929 frente a diferentes concentrações do extrato de A. oleracea.

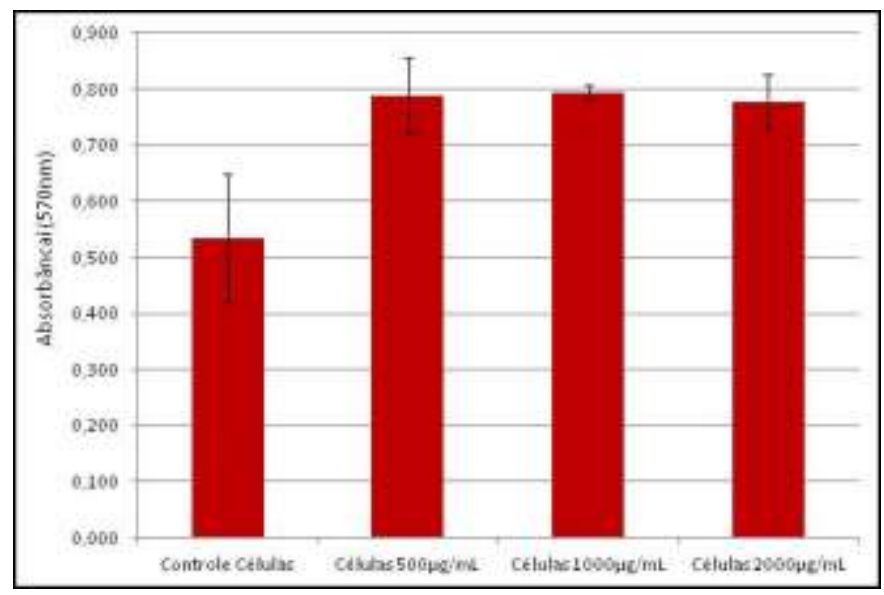

Fonte: Autores.

De acordo com os resultados obtidos verificou-se que o extrato de A. oleracea estimulou a proliferação celular quando comparado ao controle (Figura 2). Nas diferentes concentrações houve um maior estímulo quando comparado ao controle, mas não houve diferença significativa entre as concentrações de extrato de A. oleracea. 


\subsection{Viabilidade da Staphylococcus aureus com o extrato de Acmella oleracea}

A leitura da absorbância das placas foi feita em espectrofotômetro (Elisa Spectra CountTM Packard, USA) a $570 \mathrm{~nm}$. A análise estatística deu-se pelo teste ANOVA em GraphPad Prism® 5 com Significância de $\mathrm{P}<0,0001$. Após foram passados pelo teste confirmatório (Tukey de múltiplas comparações).

Figura 3 - Avaliação do crescimento da bactéria Staphylococcus aureus após a incubação de diferentes concentrações do extrato de Acmella oleracea.

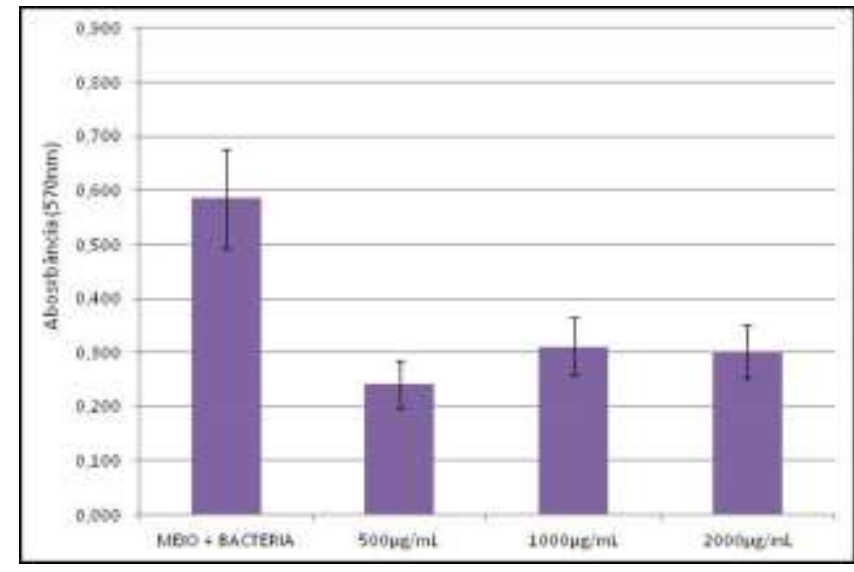

Fonte: Autores.

De acordo com os resultados obtidos (Figura 3), observou-se que houve uma diferença altamente significativa nas concentrações $500 \mathrm{ug} / \mathrm{mL}, 1000 \mathrm{ug} / \mathrm{mL}$ e $2000 \mathrm{ug} / \mathrm{mL}$ comparado ao meio+bactéria. Mas na diferença entre os grupos de 500 $\mathrm{ug} / \mathrm{mL}, 1000 \mathrm{ug} / \mathrm{mL}$ e $2000 \mathrm{ug} / \mathrm{mL}$ não foram significativas. Mesmo não sendo significativa a diferença entre os grupos, a amostra contendo $500 \mathrm{ug} / \mathrm{mL}$ foi a que apresentou menor índice de UFC.

\subsection{Co-cultivo após a incubação com extrato de Acmella oleracea}

O MTT é usado para caracterizar a toxicidade de um composto, sendo assim foi utilizado para avaliar a viabilidade celular da linhagem L929 em co-cultivo com Staphylococcus aureus, após a incubação com diferentes concentrações do extrato de Acmella oleracea.

Figura 4 - Avaliação da viabilidade celular da linhagem L929 em co-cultivo com Staphylococcus aureus, após a incubação com diferentes concentrações do extrato de Acmella oleracea.

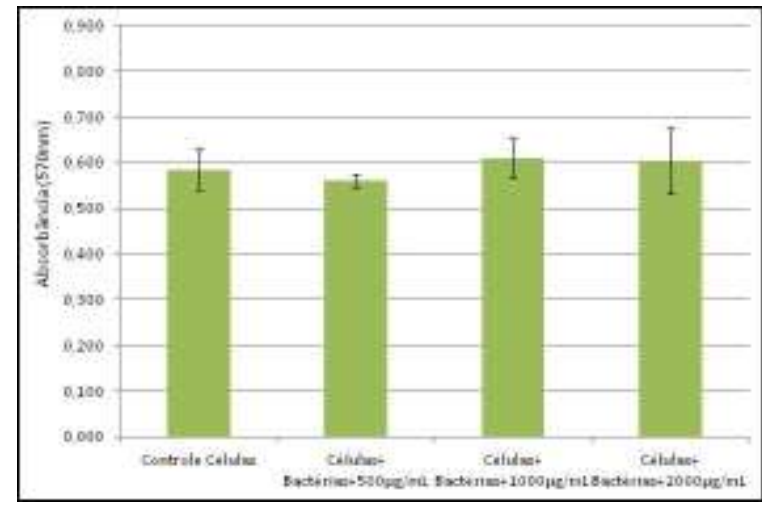

Fonte: Autores. 
De acordo com os resultados representados na figura 4, verificou-se que não houve diferença significativa entre as concentrações de extrato de A. oleracea e interação com as bactérias. A linhagem celular L929 permaneceu ativa em todos os tratamentos com viabilidade semelhante ao controle.

O crescimento bacteriano foi avaliado em co-cultivo da linhagem celular L929 após a incubação em diferentes concentrações do extrato de A. oleracea, sendo realizada a leitura do sobrenadante.

Figura 5 - Avaliação do crescimento da bactéria Staphylococcus aureus, após a aplicação do extrato de Acmella oleracea em co-cultivo com a linhagem celular L929.

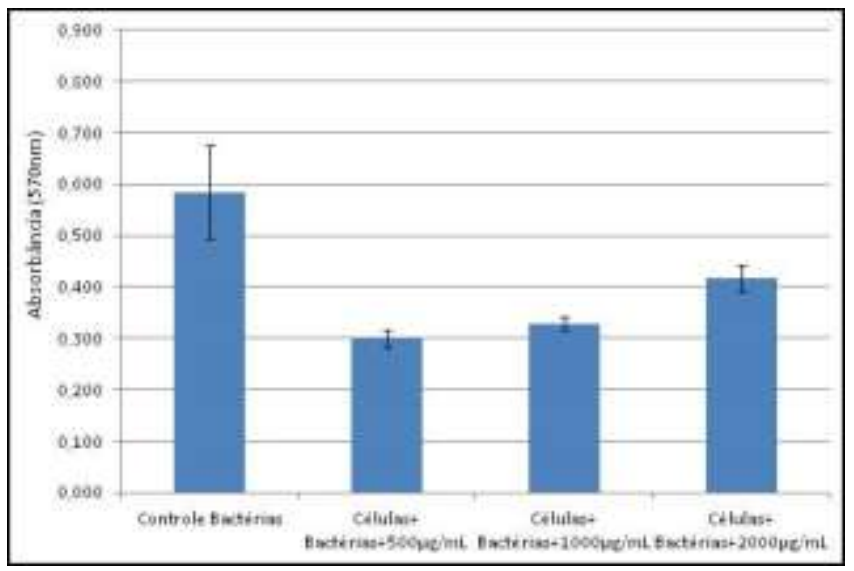

Fonte: Autores.

Em relação aos resultados obtidos (Figura 5), foi demonstrada uma diferença altamente significativa em relação ao controle bactéria com as concentrações do extrato. Verificou-se que ao se realizar o co-cultivo da S. aureus e L929, o crescimento da bactéria foi o que apresentou um menor índice de unidade formadora de colônias.

Figura 6 - Gráfico da vista geral de todos resultados obtidos.

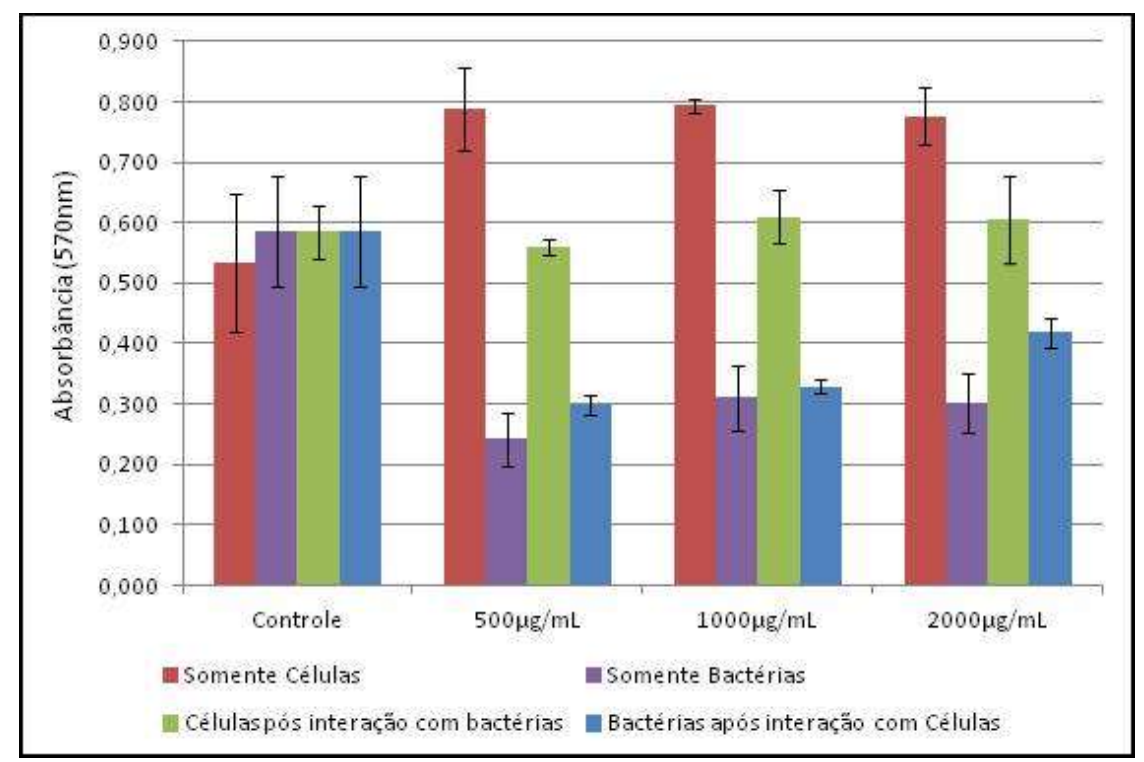

Fonte: Autores.

Os resultados apresentados na Figura 6, representam a visão geral de todos os resultados obtidos, contendo somente o controle e as concentrações de extrato $500 \mathrm{ug} / \mathrm{mL}, 1000 \mathrm{ug} / \mathrm{mL}$ e $2000 \mathrm{ug} / \mathrm{mL}$ em diferentes aplicações. Verificou-se que em todas as concentrações houve um maior estímulo nas células da linhagem L929, comparando com a bactéria $S$. aureus que 
apresentou um menor estímulo. E observou-se que quanto maior a concentração, mais a bactéria é estimulada, como na concentração de $2000 \mathrm{ug} / \mathrm{mL}$ em que, após a interação com as células, a bactéria apresentou um maior estímulo comparando as concentrações de $500 \mathrm{ug} / \mathrm{mL}$ e $1000 \mathrm{ug} / \mathrm{mL}$, porém, a linhagem celular não apresentou uma diferença significativa nas diferenças concentrações de extrato.

\section{Discussão}

O Jambu - Acmella oleracea - na medicina popular é consumido na comida ou chá para dor de dente, feridas na boca, pela sua ação anestésica, analgésico, anti-inglamatório, antifúngico, antimalárico. Um dos compostos responsáveis pelas atividades farmacológicas é o espilantol, a alquilamida mais abundante no extrato de Jambu (Yamane, 2016).

Os resultados obtidos com o ensaio MTT na concentração de $1000 \mu \mathrm{g} / \mathrm{mL}$ indicou uma diferença altamente significativa na viabilidade celular em relação as outras concentrações, onde observamos alta atividade mitocondrial. No estudo de Silva (2021) foi utilizado extrato bruto de Acmella oleracea e foi constatado que houve uma redução significativa no período de incubação de 24 horas nas concentrações de 250, 500 e $1000 \mu \mathrm{g} / \mathrm{mL}$ em relação ao grupo controle. Os métodos distintos de interação do extrato com as células L929 podem interferir nos resultados obtidos. A metodologia empregada em nossos estudos apresentou ser menos agressiva à linhagem celular L929.

A partir dos resultados obtidos com o ensaio cristal violeta, é possível notar que entre as concentrações não houve uma diferença significativa, porém apresentaram um maior estímulo comparado ao controle. Silva (2021) em seu estudo com o ensaio cristal violeta no período de 24 horas de incubação, apresentou um aumento na concentração de $500 \mu \mathrm{g} / \mathrm{mL}$.

Diversas plantas superiores e aromáticas apresentam ação antimicrobiana, associada à presença de óleos essenciais e compostos bioativos como os compostos fenólicos (Duarte et al., 2004; Balouiri et al., 2016; Sper et al., 2021). Os resultados obtidos da atividade antibacteriana na concentração de $500 \mu \mathrm{g} / \mathrm{mL}$ apresentou um menor índice de unidade formadora de colônia, porém entre os grupos de $500 \mu \mathrm{g} / \mathrm{mL}, 1000 \mu \mathrm{g} / \mathrm{mL}$ e $2000 \mu \mathrm{g} / \mathrm{mL}$ não houve uma diferença significativa. De acordo com Noor et al. (2013), aproximadamente $13 \mu \mathrm{g} / \mathrm{mL}$ de um extrato etanólico $95 \%$ de folhas de jambu apresentaram atividade antimicrobiana na bactéria Staphylococcus aureus. Em um artigo de revisão sobre a atividade citotóxica da Spilanthes acmella, os autores demonstraram que os resultados encontrados de extratos exibem variações significativas em vários testes para uma grande variedade de microrganismos (Dias et al., 2021)

Assim, os resultados obtidos do co-cultivo em S. aureus e na linhagem celular L929 após a incubação de diferentes concentrações de extrato, notou-se que com a incubação do extrato de A. oleracea houve uma alta estimulação nas células e redução do número de bactérias. Contudo, não houve uma eficiência 100\% contra a S. aureus, assim como afirmado por Bueno (2019) em que o extrato bruto de A. oleracea apresentou $100 \%$ de eficiência contra E. coli e $S$. aureus, não apresentando colônias formadas após os testes.

Baêta (2011) ao realizar o co-cultivo da bactéria Borrelia burgdorferi em células embrionárias do carrapato Dermacentor nitens, após 72 horas houve uma intensa multiplicação das espiroquetas $B$. burgdorferi. O número de bactérias $B$. burgdorferi crescidas em meio BSK, que é próprio para este tipo de bactéria, juntamente com células do carrapato, foi maior e diferiu significativamente dos outros grupos, onde receberam o meio BSK juntamente com o meio Leibovitz's L-15 B, que é próprio para a linhagem celular e inibe o crescimento bacteriano.

Assim, é importante destacar que nos resultados obtidos em nossos estudos só foi possível um maior estímulo nas células L929 comparado a S. aureus, devido a ação do extrato de A. oleracea em diferentes concentrações. 


\section{Conclusão}

A partir dos resultados obtidos pelos testes de citotoxicidade através da viabilidade celular pelo MTT, pode-se concluir que o extrato de Acmella oleracea na concentração de $1000 \mu \mathrm{g} / \mathrm{mL}$ interferiu na linhagem L929, apresentando crescimento significativo. No teste de cristal violeta, conclui-se que o extrato nas concentrações de 500,1000 e $2000 \mu \mathrm{g} / \mathrm{mL}$ não interferiu na linhagem L929. Já em relação ao resultado a partir da atividade antibacteriana, conclui-se que o extrato na concentração $500 \mu \mathrm{g} / \mathrm{mL}$ interferiu na bactéria Staphylococcus aureus apresentando um menor índice de unidade formadora de colônias.

Após o co-cultivo da linhagem L929 e Staphylococcus aureus em diferentes concentrações de extrato, o teste apresentou redução no número de bactérias, porém gerando um aumento no estímulo na linhagem L929. Entretanto, na concentração de $2000 \mu \mathrm{g} / \mathrm{mL}$ observamos um crescimento no número de bactérias, após interação com a linhagem L929, devido a isso, conclui-se que em maiores concentrações o extrato de Acmella oleracea pode aumentar o estímulo tanto de bactérias e células. Devido a isso, sugerimos a utilização de menores concentrações do extrato de A. oleracea

Portanto, a ação do extrato de Acmella oleracea no co-cultivo em S. aureus e a linhagem celular L929, indicou que o extrato da planta apresentou uma atividade antimicrobiana sem interferir na linhagem celular L929, demonstrando a importância da planta e que pode ser utilizada e aplicada contra a celulite infecciosa.

A partir destes resultados é de extrema importância a continuidade dos estudos a fim de verificar tanto na linhagem celular L929 quanto nas bactérias $S$. aureus os mecanismos de ativação e morte celular induzidas pelo extrato de A. oleracea. Conhecer estes mecanismos poderá aumentar ainda mais a efetividade do tratamento da celulite infecciosa a partir de extratos vegetais.

\section{Referências}

Arcos, M. L., Ossa, F. \& Díaz, T. E., (2004). Criopreservación de aislados nativos de la bacteria ruminal Fibrobacter succinogenes. Revista Corpoica. 5, 60-3.

Baêta, B. A., (2011). Co-cultivo de Borrelia burgdorferi (Spirochaetales: Spirochaetaceae) em cultura primária de células embrionárias de Dermacentor nitens (Acari: Ixodidae). Dissertação em Mestrado, Universidade Federal Rural do Rio de Janeiro, Curso de Pós-Graduação em Ciências Veterinárias. 41 págs.

Balouiri, M., Sadiki, M. \& Ibnsouda, S. K., (2016). Methods for in vitro evaluating antimicrobial activity: A review. J. Pharm. Anal. 6(2), 71-9.

Brum, C. F., Silva, T. C. T., Matos, T. S. R.\& Moura, T. S., (2016). Estudo de caso aplicado à sistematização da assistência de enfermagem em paciente com celulite infecciosa. Revista Rede de Cuidados em Saúde. 10(3), 1-3.

Castro-Silva, I. I., Alves, G. G., Castro, L. O., Ramirez, C. M. \& Granjeiro, J. M., (2009). Preliminary analysis of the influence of low intensity laser (GaAlAs) in proliferation of human deciduous dental pulp derived cells. Innov. Implant. J., Biomater. Esthet. 4(2), 48-52.

Chagas, M. M., (2020). Atividade antibacteriana do extrato vegetal de jambu (Spilanthes acmella) em isolados de Staphylococcus spp. de amostras de leite de bovinos. Universidade Federal do Amazonas, Faculdade de Ciências Agrárias, Programa de Pós-graduação em Ciência animal. Dissertação de Mestrado na área de concentração Biotecnologia e Microbiologia. 51 págs.

Dias, R. S., Brasil, D. S. B. \& Martelli, M. C., (2021). Atividades biológicas da espécie Spilanthes acmella: uma revisão. Research, Society and Development, 10(14), 1-19.

Duarte, M. C. T., Figueira, G. M., Pereira, B., Magalhães, P. M. \& Delarmelina, C., (2004). Atividade antimicrobiana de extratos hidroalcólicos de espécies da coleção de plantas medicinais CPQBA/UNICAMP. Rev. Bras. Farmacogn. 14(1), 6-8.

Ferreira, M. J. G., Dias, F. G. B., Santos, S. M., Menezes, R. C. S., Silva, L. M. R. \& Figueiredo, E. A. T., (2020). Evaluation of medicinal plants as potential food antimicrobial additives. Research, Society and Development, 9(5), 1-14. 2020

Gelatti, L. C., Bonamigo, R. R., Becker, A. P. \& D’azevedo, P. A., (2009). Staphylococcus aureus resistentes à meticilina: disseminação emergente na comunidade. An. Bras. Dermatol. 84(5), 501-6.

Haida, K. S., Parzianello, L., Werner, S., Garcia, D. R. \& Inácio, C. V., (2007). Avaliação in vitro da atividade antimicrobiana de oito espécies de plantas medicinais. Arq. Ciênc. Saúde Unipar, 11(3), 185-92.

Noor, J., Razia, K., Siraj, A. \& Anwar, S., (2013). Evaluation of antibacterial potential of medicinal plant Spilanthes acmella Murr. and it's in vitro raised callus against resistant organisms especially those harbouring bla genes. Journal of Applied Pharmaceutical Science. 3(10), 119-24. 
Research, Society and Development, v. 10, n. 16, e565101624178, 2021

(CC BY 4.0) | ISSN 2525-3409 | DOI: http://dx.doi.org/10.33448/rsd-v10i16.24178

Martins, M. C. \& Garlet, T. M. B., (2016). Desenvolvendo e divulgando o conhecimento sobre plantas medicinais. Revista Eletrônica em Gestão, Educação e Tecnologia Ambiental Santa Maria, 20(1), 438-48.

Meireles, S. C. T. S. \& Mejia, D. P. M., (2016). A utilização de princípios ativos na Cosmetologia - Os benefícios do Jambu. Faculdade Ávila.

Pereira, A. S., Shitsuka, D. M., Parreira, F. J. \& Shitsuka, R. (2018). Metodologia da pesquisa científica. Ed. Santa Maria, RS: UFSM, NTE.

Ojeda, C. P. O., (2017). Potencial biotecnológico dos microrganismos endofíticos isolados do jambú (Acmella ciliata (kunth) cass.) para controle de microrganismos patógenos. Universidade do Estado do Amazonas, Programa de Pós-graduação em Biotecnologia e Recursos Naturais. Dissertação de Mestrado em Biotecnologia e Recursos Naturais da Amazônia. 68 págs.

Pires, C. A., Santos, M. A. L., Oliveira, B. F., Souza, C. R., Belarmino, L. N. M. \& Martins, M. F., (2015). Primary bacterial skin infections: profile of the cases assisted in a dermatology service in the Amazon Region, Brazil. Rev. Pan-Amaz. Saúde, Ananindeua, 6(2), 45-50.

Santos, A. L., Santos, D. O., Freitas, C. C., Ferreira, B. L. A., Afonso, I. F., Rodrigues, C. R. \& Castro, H. C., (2007). Staphylococcus aureus: visiting a strain of clinical importance. J.Bras Patol Med. Lab., 43(6), 413-23.

Silva, C. A. P., (2021). Desenvolvimento de biomaterial à base de Acmella oleracea (L.) R. K. JANSEN com atividades cicatrizante, antibacteriana e antitumoral. Tese de doutorado ao Programa de Pós-graduação em Engenharia Biomédica da Universidade do Vale do Paraíba (Univap). 91 págs.

Souza, C. S., (2003). Infecções de tecidos moles - Erisipela. Celulite. Síndromes infecciosas mediadas por toxinas. Medicina, Ribeirão Preto, $36,351-6$.

Sper, F. L., Amêndola, I., Ramos, L. P., Santos, J. G., Freitas, E. T., Meccatti, V. M., Ferraz, L. F. F., Oliveira, J. R., Santamaria, M. P., Ribeiro, M. C. M. \& Oliveira, L. D., (2021). Effect of Stryphnodendron adstringens (Mart.) Coville extract in aerobic and anaerobic microorganisms and mammalian cells. Research, Society and Development, 10 (11), 1-17.

Yamane, L. T., (2016). Avaliação de formulações tópicas contendo extrato etanólico de Acmella oleracea (L.) R. K. JASEN (Jambu), associado a óleo essencial de Achyrocline satureioides LAM (macela). Dissertação em mestrado pela Universidade Estadual de Campinas, Faculdade de Ciências Médicas. 81 págs. 